\title{
A CLINICAL STUDY OF NON-VENEREAL GENITAL DERMATOSES
}

\author{
A. N. M. Maalik Babu1, Revathy Mathan², P. P. Ramasamy³ \\ ${ }^{1}$ Senior Resident, Department of Sexually Transmitted Disease, Tirunelveli Medical College Hospital. \\ ${ }^{2}$ Associate Professor, Department of Dermatology, Govt. Theni Medical College Hospital. \\ 3Professor, Department of Dermatology, Coimbatore Medical College Hospital.
}

ABSTRACT

\section{BACKGROUND}

Most dermatological diseases generally occur elsewhere and also involve the genitalia. If the lesion is present exclusively on genitalia, it is a difficult task for the treating doctor to differentiate non venereal from venereal genital lesions.

Aim is to study the clinical pattern and prevalence of non-venereal genital dermatoses.

\section{MATERIALS AND METHODS}

It is a descriptive study of adult new cases with genital lesions attending Skin and STD Outpatient Clinic of Coimbatore Medical College Hospital for a period of one year from August 2013 to July 2014. Clearance was obtained from Ethical Committee.

\section{RESULTS}

A total of 150 cases (114 males, 36 females) with non-venereal genital dermatoses were encountered in our study. Prevalence of the non-venereal genital dermatoses in the study was 2.6 per 1000 cases. Male-to-Female ratio of patients in our study was 3.16:1. Majority of the patients were found in the age group of 33 to 42 years [42 (28\%)]. Commonest non-venereal genital dermatosis was found to be scabies occurring in $19(12.6 \%)$ patients. Pearly penile papule was found to be more common [10 (6.6\%)] among benign conditions and normal variants. Among inflammatory conditions and miscellaneous groups, contact dermatitis and vitiligo were the commonest conditions respectively. One case of verrucous carcinoma of penis was seen.

\section{CONCLUSION}

All lesions occurring over genitalia are not sexually transmitted. Scabies was the most common non-venereal genital dermatosis in our study. Identifying the common non-venereal genital conditions will also remove venereophobia.

\section{KEYWORDS}

Non-Venereal, Genital Dermatosis, Genitalia.

HOW TO CITE THIS ARTICLE: Babu ANMM, Mathan R, Ramasamy PP. A clinical study of non-venereal genital dermatoses. J. Evolution Med. Dent. Sci. 2016;5(90):6694-6697, DOI: 10.14260/jemds/2016/1514

\section{BACKGROUND}

Non-venereal genital dermatoses are often confused with venereal diseases, which may be a cause for concern to the patients and also serve as a diagnostic dilemma to the physician. The non-venereal disorders cause mental distress and guilt feeling in patients who believe that they have developed sexually transmitted disease. The present study attempts to know about the prevalence and clinical pattern of non-venereal genital dermatoses. A comprehensive understanding of the various presentations help the physician to effectively manage the conditions and also relieves the patient's anxiety. Based on aetiopathogenesis, Fitz Patrick and Gentry ${ }^{1}$ classified non-venereal genital dermatoses into the following categories:

- Benign conditions and normal variants.

- Congenital anomalies.

- Infections and infestations.

- Inflammatory conditions.

- Premalignant conditions.

Financial or Other, Competing Interest: None.

Submission 06-10-2016, Peer Review 30-10-2016,

Acceptance 05-11-2016, Published 09-11-2016.

Corresponding Author:

A. N. M. Maalik Babu,

\#14, Balajinagar, High Ground,

Tirunelveli-627011, Tamilnadu.

E-mail:maalikbabu7@gmail.com

DOI: $10.14260 /$ jemds/2016/1514
- Malignant conditions.

- Miscellaneous lesions.

\section{MATERIALS AND METHODS}

It is a descriptive study of adult new cases with genital lesions attending Skin and STD Outpatient Clinic of Coimbatore Medical College Hospital for a period of one year from August 2013 to July 2014.

\section{Inclusion Criteria}

Male and Female patients above 12 years of age.

\section{Exclusion Criteria}

- Male and Female patients below 12 years of age.

- Transgenders.

- Patients presenting with classical sexually transmitted infection.

- $\quad$ HIV, VDRL reactive patients.

\section{OBSERVATIONS AND RESULTS}

A total of 150 patients with non-venereal genital dermatoses were enrolled in this study. Among them males and females were 114 and 36 respectively. Prevalence of non-venereal genital dermatoses in the study was 2.6 per 1000 cases. Maleto-Female ratio of patients with non-venereal genital dermatoses in study was 3.16:1. Age of the patients with nonvenereal genital dermatoses in this study was between 12 and 72 years and their mean age was 40.74 years. Scabies 
was found in 19 (12.6\%) patients and it was the commonest non-venereal genital dermatosis among 150 cases. This was followed by Vitiligo (17 cases) and Candidosis (12 cases). A total of 29 cases were found in the category of benign conditions and normal variants. Pearly penile papule was the commonest dermatosis among them. A total of 41 cases were found in the category of infections and infestations. Scabies was the commonest dermatosis among them. A total of 50 cases were found in the category of inflammatory conditions. Contact dermatitis was found in 8 patients and it was the most common non-venereal dermatosis among them. A total of 29 cases were found in the category of miscellaneous conditions. Among them vitiligo was seen in more number of patients (17 cases). Six interesting cases documented in our study were tick bite, lymphangiectasia of scrotum, erythroderma (Mycosis fungoides), verrucous carcinoma of penis, Fournier's gangrene of scrotum and Hailey-Hailey disease.

\begin{tabular}{|c|c|c|c|c|}
\hline $\begin{array}{l}\text { Sl. } \\
\text { No. }\end{array}$ & $\begin{array}{c}\text { Genital } \\
\text { Conditions } \\
\end{array}$ & Male & Female & Total \\
\hline 1. & Pearly penile papule & 10 & - & $10(34.4 \%)$ \\
\hline 2. & $\begin{array}{c}\text { Angiokeratoma of } \\
\text { Fordyce }\end{array}$ & 5 & - & $5(17.2 \%)$ \\
\hline 3. & Phimosis & 5 & - & $5(17.2 \%)$ \\
\hline 4. & Fordyce spots & 4 & - & $4(13.7 \%)$ \\
\hline 5. & Paraphimosis & 2 & - & $2(6.9 \%)$ \\
\hline 6. & Lymphangiectasia & 1 & - & $1(3.4 \%)$ \\
\hline 7. & Vulval skin tag & - & 1 & $1(3.4 \%)$ \\
\hline 8. & Bartholin's cyst & - & 1 & $1(3.4 \%)$ \\
\hline \multicolumn{4}{|c|}{$\begin{array}{ll}\text { Total } \\
\end{array}$} & $29(100 \%)$ \\
\hline
\end{tabular}

\begin{tabular}{|c|c|c|c|c|}
\hline $\begin{array}{c}\text { Sl. } \\
\text { No. }\end{array}$ & $\begin{array}{c}\text { Genital } \\
\text { Conditions }\end{array}$ & Male & Female & Total \\
\hline 1. & Scabies & 12 & 7 & $19(47.5 \%)$ \\
\hline 2. & Candidosis & 8 & 4 & $12(30 \%)$ \\
\hline 3. & Furunculosis & 2 & 2 & $4(10 \%)$ \\
\hline 4. & Tinea cruris & 2 & 1 & $3(7.5 \%)$ \\
\hline 5. & $\begin{array}{c}\text { Fournier's } \\
\text { gangrene }\end{array}$ & 1 & 0 & $1(2.5 \%)$ \\
\hline 6. & Tick bite & 1 & 0 & $1(2.5 \%)$ \\
\hline 7. & $\begin{array}{c}\text { Molluscum } \\
\text { contagiosum }\end{array}$ & 1 & 0 & $1(2.5 \%)$ \\
\hline \multicolumn{5}{|c|}{ Table 2. List of Infections and Infestations } \\
\hline
\end{tabular}

\begin{tabular}{|c|c|c|c|c|}
\hline $\begin{array}{c}\text { Sl. } \\
\text { No. }\end{array}$ & Genital Conditions & Male & Female & Total \\
\hline 1. & Contact dermatitis & 4 & 4 & $8(16 \%)$ \\
\hline 2. & Lichen planus & 4 & 2 & $6(12 \%)$ \\
\hline 3. & Fixed drug eruption & 5 & - & $5(10 \%)$ \\
\hline 4. & Lichen simplex chronicus & 5 & - & $5(10 \%)$ \\
\hline 5. & $\begin{array}{c}\text { Lichen sclerosus et } \\
\text { atrophicus }\end{array}$ & 3 & 2 & $5(10 \%)$ \\
\hline 6. & Psoriasis & 4 & - & $4(8 \%)$ \\
\hline 7. & Hailey-Hailey disease & 1 & 2 & $3(6 \%)$ \\
\hline 8. & Seborrhoeic dermatitis & 2 & 1 & $3(6 \%)$ \\
\hline 9. & $\begin{array}{c}\text { Stevens-Johnson } \\
\text { syndrome }\end{array}$ & 1 & 1 & $2(4 \%)$ \\
\hline 10. & Pemphigus vulgaris & 2 & - & $2(4 \%)$ \\
\hline 11. & Erythroderma & 1 & 1 & $2(4 \%)$ \\
\hline
\end{tabular}

\begin{tabular}{|c|c|c|c|c|}
\hline 12. & Zoon's balanitis & 2 & - & $2(4 \%)$ \\
\hline 13. & Bullous pemphigoid & - & 1 & $1(2 \%)$ \\
\hline 14. & Lichen nitidus & 1 & - & $1(2 \%)$ \\
\hline 15. & Erythema multiforme & 1 & - & $1(2 \%)$ \\
\hline & & & Total & $\begin{array}{c}50 \\
(100 \%)\end{array}$ \\
\hline
\end{tabular}

\begin{tabular}{|c|c|c|c|c|}
\hline $\begin{array}{c}\text { Sl. } \\
\text { No. }\end{array}$ & Genital Conditions & Male & Female & Total \\
\hline 1. & Vitiligo & 11 & 6 & $\begin{array}{c}17 \\
(58.6 \%)\end{array}$ \\
\hline 2. & Sebaceous cyst & 6 & - & $\begin{array}{c}6 \\
(20.6 \%)\end{array}$ \\
\hline 3. & Scrotal calcinosis & 4 & - & $\begin{array}{c}4 \\
(13.7 \%)\end{array}$ \\
\hline 4. & Penile melanosis & 2 & - & $\begin{array}{c}2 \\
(6.9 \%)\end{array}$ \\
\hline \multicolumn{4}{|c|}{ Table 4. List of Miscellaneous Conditions } \\
\hline
\end{tabular}

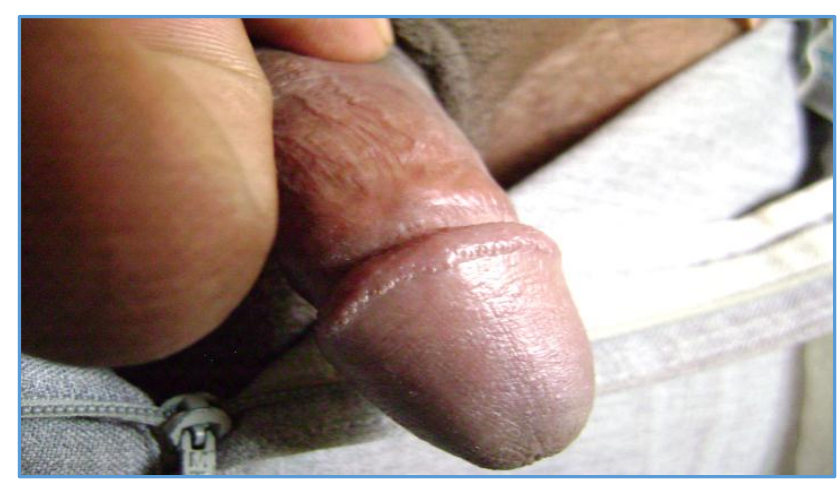

Figure 1. Pearly Penile Papule

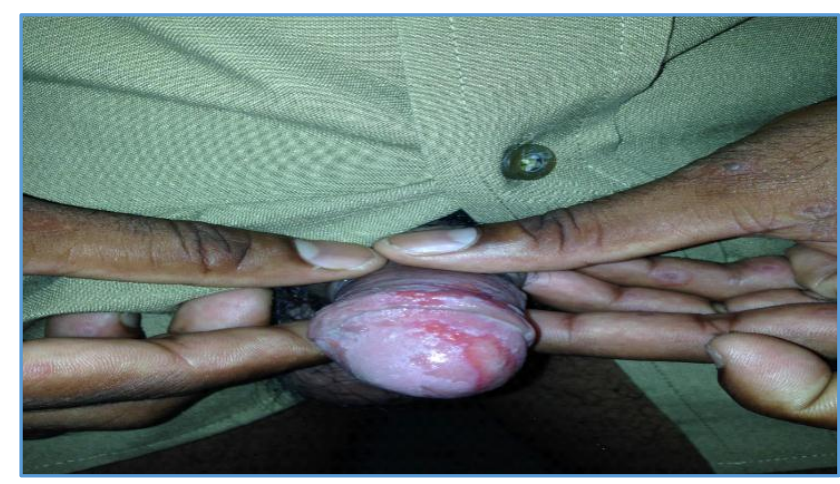

Figure 2. Erythema Multiforme

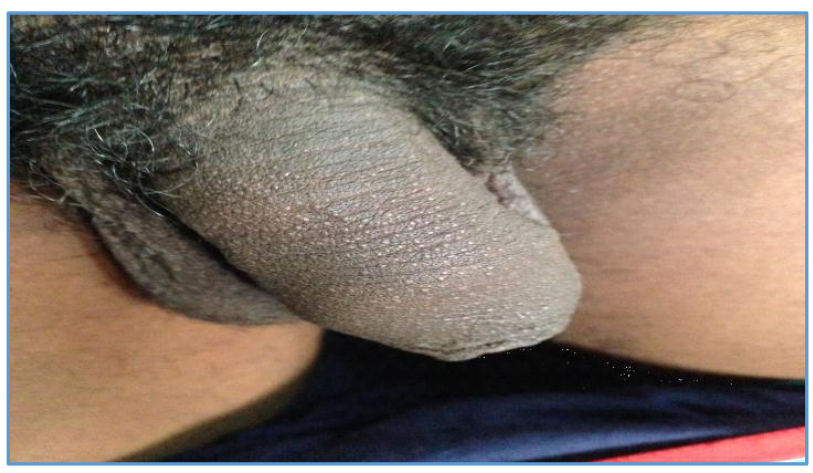

Figure 3. Lichen Nitidus 


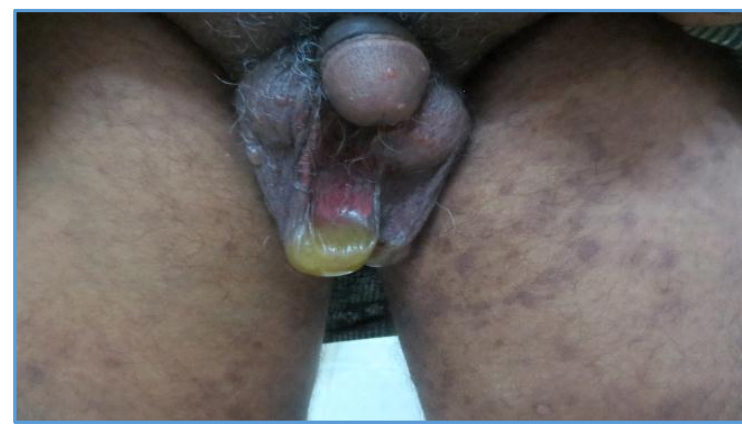

Figure 4. Pemphigus Vulgaris

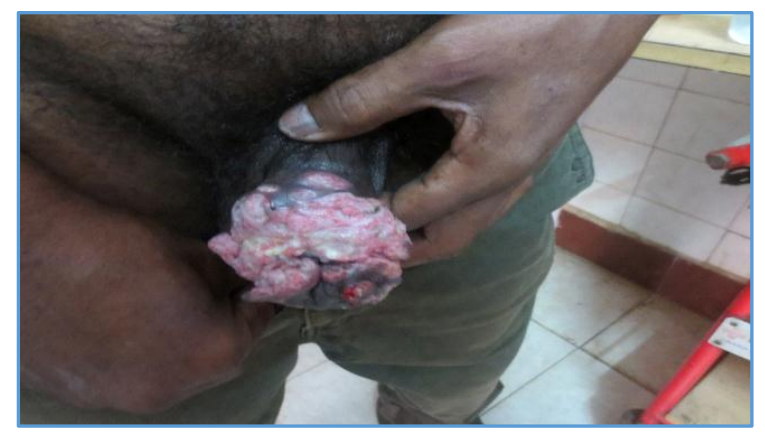

Figure 5. Verrucous Carcinoma

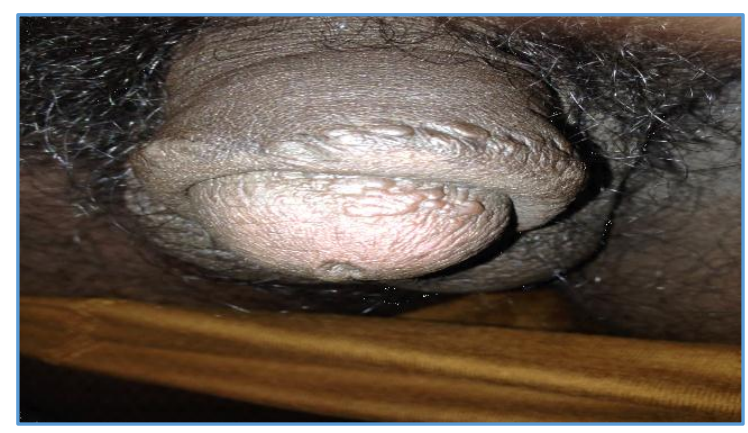

Figure 6. Bullous FDE

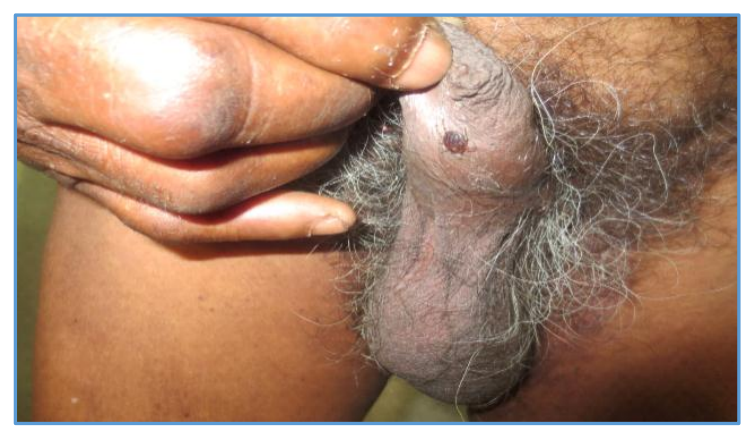

Figure 7. Tick Bite

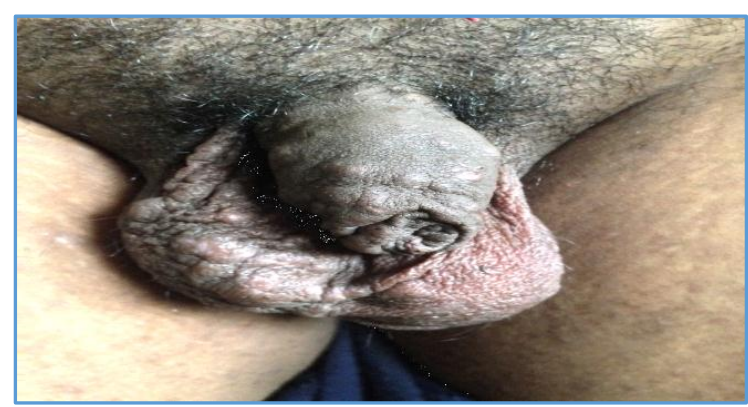

Figure 8. Nodular Scabies

\section{DISCUSSION}

In our study, age of the patients with non-venereal genital dermatoses were found between 12 and 72 years. Mean age of the patients with non-venereal genital dermatoses was 40.74 years. In a study by Basheer Ahammed et al patients were aged between 8 months and 77 years. We found 19 $(12.6 \%)$ cases of scabies and it was the most common nonvenereal genital dermatosis in our study. In a study by Basheer Ahammed et al, there were more number of patients with genital vitiligo. Neerjapuri et al reported scrotal dermatitis as the commonest non-venereal disease in their study. ${ }^{2}$ Ten $(6.6 \%)$ cases of pearly penile papule were seen in our study and it was the commonest normal variant. Khoo $\mathrm{L}$. S. et al reported similar findings in their study. ${ }^{3}$ In our study, we found 5 cases $(3.3 \%)$ of phimosis and recurrent candidal infection was the main aetiology for phimosis; 3 out of 5 cases in our study were diabetic and it could be the cause for candidal infection. In a study by Basheer Ahammed et al, 4 cases of phimosis have been reported. In our study, we reported 4 cases (2.6\%) of Fordyce spot. Basheer Ahammed et al found a case of Fordyce spot in their study. In our study, we found a case of Lymphangiectasia over scrotum. He had received radiotherapy a month back. Horinaga $M$ et al have reported a case of scrotal elephantiasis after treatment of penile carcinoma. 4 We found a rare case of Fournier's gangrene in our study. In their study Acharya et al found a case of Fournier's gangrene, which was similar to our study. ${ }^{5}$ We found a case of tick bite who presented with pain over penis and scrotum and a similar case was reported by Asvestis C et al. ${ }^{6}$ We encountered one case of FDE with bullous lesions over glans, prepuce with history of intake of cotrimoxazole similar to study by Basheer Ahammed et al. We encountered 2 cases of pemphigus vulgaris with involvement of penis and scrotum. Basheer Ahammed et al reported one female patient with pemphigus vulgaris. Incidence of lichen nitidus was almost same as in the study by Karthikeyan $\mathrm{K}$ et $\mathrm{al}^{7}$ and Basheer Ahammed et al reported 3 cases of lichen nitidus. We found a case of erythema multiforme with history of intake of cotrimoxazole. Kedar Saraf et al reported a case of erythema multiforme with history of intake of cotrimoxazole. 8 We encountered a case of verrucous carcinoma of penis similar to study by Neerjapuri et al. We found 17 cases (11.3\%) of vitiligo including 11 males and 6 females in our study. Basheer Ahammed et al and Karthikeyan $\mathrm{K}$ et al reported 23 cases (13.6\%) and 16 cases $(16 \%)$ in their studies respectively. We found 4 cases $(3.5 \%)$ of scrotal calcinosis, which is similar to the study by Karthikeyan $\mathrm{K}$ et al. In a study by Basheer Ahammed et al, 10 cases of scrotal calcinosis was reported.

\section{CONCLUSION}

All lesions occurring over genitalia are not sexually transmitted. All clinicians should have an open mind to look for these conditions and treat with appropriate drugs. This unbiased approach will give more confidence to the patient to come for medical help, because otherwise they will have shyness and fear to approach the physician. Knowing about the prevalence, clinical and aetiological characteristics of various non-venereal genital dermatoses are helpful in arriving at a diagnosis and also creating awareness among patients to improve their personal hygiene and social habits. 
Some patients particularly females who have fear and lack of knowledge need more attention, privacy and education.

\section{ACKNOWLEDGEMENT}

I would like to thank, Dr. P. P. Ramasamy M. D., D. D., Professor and Head of Department of Dermatology, Venereology and Leprology, Coimbatore Medical College Hospital from the bottom of my heart for his scholarly advice and timely assistance during the preparation of this article. I would like to express my gratitude to Dr. M. Revathy M. D., Associate Professor of Department of Dermatology, Govt. Theni Medical College for her constant encouragement and valuable suggestions during the period of this study. I am very grateful to all patients for their co-operation and participation in the study.

\section{REFERENCES}

1. Fitzpatrick JA, Gentry RM. Non venereal disease of male genitalia. Dermatology. $3^{\text {rd }}$ edn. Vol II. Philadelphia: Saunders 1992:1008-15.

2. Puri N, Puri A. A study on non venereal genital dermatoses in north India. Our Dermatol Online 2012;3(4):304-7.
3. Khoo LS, Cheong WK. Common genital dermatoses in male patients attending a public sexually transmitted disease clinic in Singapore. Ann Acad Med Singapore 1995;24(4):505-9.

4. Horinaga M, Masuda T, Jitsukawa S. A case of scrotal elephantiasis 30 years after treatment of penile carcinoma. Hinyokika Kiyo 1998;44(11):839-41.

5. Acharya KM, Ranapara H, Sakia JJ, et al. A study of 200 cases of genital lesions of non-venereal origin. Ind J Dermatol Venereol Leprol 1998;64(2):68-70.

6. Asvestis C, Asvesti K. Acute scrotum due to tick bite. Br J Urol 1989;63(4):437.

7. Karthikeyan K, Jaisankar TJ, Thappa DM. Non-venereal dermatoses in male genital region-prevalence and patterens in a referral centre in south India. Indian J Dermatol 2001;46(1):18-22.

8. Saraf KV, Shashikanth MC, Patait M, et al. Erythema multiforme major: case report. International Journal of Oral \& Maxillofacial Pathology 2012;3(4):34-8. 